\title{
Sodium-bicarbonated mineral water reduces postprandial lipaemia in moderately hypercholesterolaemic young adults
}

\author{
L. Toxqui, A. M. Pérez-Granados, R. Blanco-Rojo and M. P. Vaquero \\ Institute of Food Science, Technology and Nutrition (ICTAN), Spanish National Research Council (CISC), \\ C/José Antonio Novais 10, 28040 Madrid, Spain
}

Mineral water consumption is essential to maintain good health. It is known that mineral waters, especially alkaline ones, have digestive effects. Although there is information on crenotherapy treatments from observational studies ${ }^{(1)}$, assays using scientific methods are scarce ${ }^{(2-4)}$. Our research group has observed that the consumption of 1 litre/d of an alkaline sodium-bicarbonated mineral water during 8 weeks, reduces cardiovascular risk in post-menopausal women and in moderately hypercholesterolaemic young adults ${ }^{(2,3)}$. In addition, Schoppen et al. ${ }^{(4)}$, observed a reduction in postprandial lipaemia in post-menopausal women who consumed 0.51 litre of the same sodiumbicarbonated mineral water with a standard meal. Therefore, the aim of this study was to investigate the effects on postprandial lipaemia of the sodium-bicarbonated mineral water, compared with a control mineral water, in moderately hypercholesterolaemic men and women.

Volunteers selected for the study had to be young ( $>18$ and $<40$ years) and with a BMI $>18$ and $<30 \mathrm{~kg} / \mathrm{m}^{2}$. None of the volunteers were diabetic, hypertensive or usual consumer of carbonated mineral water, under medication that could affect lipid metabolism or consuming functional foods that could affect lipid metabolism (food containing $n-3$ fatty acids or phytosterols). The present study was carried out with twenty-one hypercolesterolaemic young adults (ten men and eleven women). Ages of the volunteers were 28 (SD 4.5) years, total cholesterol concentration was 4.54 (SD 1.14) $\mathrm{mmol} / \mathrm{l}$ and serum TAG were 1.21 (SD 0.51) $\mathrm{mmol} / \mathrm{l}$.

The study was carried out in a two-way randomised controlled cross-over trial using two different mineral waters. Each volunteer consumed a fat-rich standard meal ${ }^{(4)}$, with 0.51 of sodium-bicarbonated mineral water from Vichy Catalán spring $\left(\mathrm{HCO}_{3}{ }^{-} 2120 ; \mathrm{Ca}^{2+}\right.$ $\left.32.0 ; \mathrm{Mg}^{2+} 9.4 ; \mathrm{Na}^{+} 1102 ; \mathrm{K}^{+} 49.5 \mathrm{mg} / \mathrm{l}\right)$ and control mineral water with low mineral content $\left(\mathrm{HCO}_{3}{ }^{-} 104 ; \mathrm{Ca}^{2+} 33.4 ; \mathrm{Mg}^{2+} 5.0 ; \mathrm{Na}^{+}\right.$ $\left.8.7 ; \mathrm{K}^{+} 2.0 \mathrm{mg} / \mathrm{l}\right)$. Blood samples were obtained at basal and 30, 60 and $120 \mathrm{~min}$ after the consumption of the meal with the corresponding water. Serum TAG were determined by an automatic analyser.

Results show a reduction in postprandial serum TAG at 30 and 60 min with the sodium-bicarbonated mineral water compared with the control water (paired Student's $t$-test, $P=0.01, P=0.03$, respectively). This is in agreement with the results obtained previously in postmenopausal women ${ }^{(4)}$.

When data from Schoppen et al. ${ }^{(4)}$ and those from the present study are pooled ( $n$ 39), a clear influence of the bicarbonated mineral water in the reduction of postprandial lipaemia was shown. Significant time and water effects were observed (ANOVA, $P<0.001$, $P=0.021$, respectively), and the differences between waters were significant at 30 and 60 min (paired Student's $t$-test, $P=0.002$, for both). TAG levels were reduced in $72 \%$ of the post-menopausal women and in $66 \%$ of the young adults, thus the water effect appears less pronounced in the younger moderately hypercholestolaemic subjects than in the post-menopausal women.

Therefore, it is confirmed that this sodium-bicarbonated mineral water reduces postprandial TAG in adults with moderate cardiovascular risk. The proposed mechanism of action is that the alkaline nature of this mineral water may reduce fat and cholesterol absorption.

The study was supported by Vichy Catalán, Spain. L Toxqui was supported by a JAE-predoc grant from European Social Fund (ESF).

1. Capurso A, Solfrizzi V, Panza F et al. (1999) Aging 11, 273-276.

2. Schoppen S, Pérez-Granados AM, Carbajal A et al. (2004) J Nutr 135, 1058-1063.

3. Pérez-Granados AM, Navas-Carretero S, Schoppen S et al. (2010) J Nutr Biochem 21, 948-953.

4. Schoppen S, Pérez-Granados AM, Carbajal A et al. (2005) Br J Nutr 94, 582-587. 